\title{
perifèria
}

Número 17, diciembre 2012

revistes.uab.cat/periferia

\section{La metodología utilizada en un trabajo etnográfico en la Ciudad Autónoma de Melilla}

\author{
Francesco B. Bondanini
}

Universidad de Granada ${ }^{1}$

\begin{abstract}
Resumen
El objetivo de este artículo es describir la metodología utilizada en el trabajo de campo llevado a cabo en la Ciudad Autónoma de Melilla (España). En la investigación, que es parte de la tesis doctoral que estoy realizando en el Departamento de Antropología Social de la Universidad de Granada, se indaga en la cotidianidad de los migrantes que viven en el Centro de Estancia Temporal de Inmigrantes (CETI) de la ciudad; realizo un trabajo etnográfico cualitativo que se basa en entrevistas en profundidad y en la observación participante, que utiliza además, herramientas audiovisuales, artísticas, y que pone el acento en la participación activa de los migrantes en la investigación, para estudiar a fondo la construcción identitaria en esta fase de tránsito en su trayecto migratorio.
\end{abstract}

Palabras clave: Trabajo etnográfico, migración, construcción identitaria, arte y audiovisuales.

\begin{abstract}
The aim of this article is to describe the methodology used along the fieldwork done in the Autonomous City of Melilla (Spain). The research is part of the PhD thesis I am doing within the Social Anthropology Department of the University of Granada (Spain). I study the everyday lives of the migrants living in the CETI (Temporary Permanence Camp, as per its Spanish acronym) of the city; I conduct an ethnographic-qualitative work based on participant observation and interviews; I also use audiovisuals and art and I specially focus on the participation of the migrant in the research, to delve into the identity formation in migration's transit phase.
\end{abstract}

Keywords: Ethnography, migration, identity, audiovisual and art.

\footnotetext{
${ }^{1}$ Enviar correspondencia a Francesco B.Bondanini: fbondanini(at)gmail.com
} 


\section{perifèria}

Número 17, diciembre 2012

revistes.uab.cat/periferia

\section{Introducción}

La tesis pretende analizar la situación de los migrantes dentro de un contexto coercitivo y que tiende a marginarles, profundizando en las estrategias individuales y del grupo que adoptan en su condición de aislamiento en la Ciudad Autónoma y, en particular, en el CETI en el cual se encuentran durante el periodo de su estancia en la ciudad. Estos lugares se configuran como espacios para inmovilizar la humanidad "en exceso" (Rahola, 2003). En este sentido, el gobierno español selecciona la movilidad de las personas que están en estos campos controlando, en definitiva, sus desplazamientos, la permanencia, la expulsión o la libertad, siguiendo pautas que toman en consideración aspectos específicos de cada uno o de cada grupo, y del momento histórico y político.

El trabajo se propone diferentes objetivos: a nivel general, estudiar las migraciones internacionales actuales hacia Europa, haciendo hincapié en algunos puntos del mapa europeo, es decir sus fronteras, y profundizando además en los espacios de confinamiento que surgen en estos lugares al borde del continente. Asimismo, se propone como objetivo específico analizar la construcción identitaria de los migrantes en estos espacios, durante el tiempo de espera en la ciudad, que no está prefijado, sino que puede variar desde pocos días hasta años.

En el artículo me detengo de modo particular en la importancia del enfoque metodológico utilizado en el trabajo de campo llevado a cabo a lo largo de los años 2010 y 2011, describiendo: las técnicas elaboradas, las sensaciones vividas y las dificultades $y$, finalmente, subrayando mi rol de investigador en este contexto; el artículo no quiere ser una recopilación de teorías o técnicas metodológicas, sino que quiere mostrar el posicionamiento elegido para desarrollar la investigación.

\section{Contexto de análisis}

"Melilla es un enclave español situado geográficamente en el continente africano (...) ocupa poco más de diez kilómetros cuadrados de territorio y limita por un lado con el mar Mediterráneo y por la parte restante con Marruecos. Es interesante destacar cómo desde las playas (por los dos lados) se aprecian, por un lado 


\section{perifèria}

Número 17, diciembre 2012

\section{revistes.uab.cat/periferia}

Mariguari, unas rocas montañosas en Marruecos y por el otro, el puerto de Nador. Desde muchos puntos de la ciudad se puede ver el monte Gurugú. De la misma forma, desde estos lugares se puede admirar la ciudad española. Los migrantes pueden vivir en el monte un tiempo, a veces largo, antes de alcanzar Melilla a través del puerto de Nador, Mariguari o a través de las fronteras terrestres ${ }^{2}$. Las 4 fronteras distan pocos kilómetros entre ellas y las unen una valla que rodea y cierra Melilla dentro de un recinto metálico" (Bondanini 2011:613). La ciudad puede representar para las personas migrantes ${ }^{3}$, de igual forma, una puerta para Europa o un limbo que se prolonga de forma impensable, una fase de transición (o fase liminal) que a veces llega a convertirse en una "condición permanente" (Turner 1988:114), una ilusión que no se materializa y que se desvanece poco a poco en una frustrante espera en el Campo ${ }^{4}$. Intento analizar algunas características y aspectos de la vida (social) en este lugar de tránsito, que lo convierte en una etapa de la inmigración a Europa, un lugar donde ésta se detiene, un lugar símbolo de la "fortaleza" que se abre en su interior, clausurándose al exterior.

La vida de los migrantes se detiene en la ciudad, se vive constantemente con el miedo a ser expulsados. La precariedad hace difícil el trabajo de adaptación y es una estrategia que fomenta la desmotivación, la marginalidad en los migrantes, que en muchos casos esperan en el mismo Campo la llegada de su expulsión; una espera que en la mayoría de los casos observados es larga y, al mismo tiempo, insoportable para ellos. La desesperación viene de la falta de respuestas, de la falta de comunicación entre los distintos agentes, de la invisibilidad dentro de un Campo que es un espacio donde convivir con la desilusión de los demás.

\footnotetext{
${ }^{2}$ Los pasos fronterizos entre Marruecos y Melilla son: Beni Enzar, Mariguari, Barrio Chino y Farhana.

${ }^{3}$ A lo largo del artículo me refiero a los migrantes, haciendo referencia exclusivamente a las personas que viven en el CETI. Los nombres de las personas entrevistadas que aparecen en el artículo han sido cambiados.

${ }^{4}$ Utilizo la expresión Campo como sinónimo de Centro y de CETI (Centro de Estancia Temporal de Inmigrantes).
} 


\section{perifèria}

Número 17, diciembre 2012

revistes.uab.cat/periferia

\section{El trabajo de campo}

Mi relación con Melilla comienza con una primera visita a mitad del mes de diciembre del 2009 cuando alcancé, después de nueve horas de barco, el puerto de la ciudad. Después de la primera visita en diciembre, volví durante una semana en el mes de febrero de 2010 para retomar las entrevistas y contactar con otras personas que podrían informarme sobre el tema. Desde julio de 2010 hasta principios de abril de 2011 viví prácticamente de forma continua en la ciudad autónoma, llevando a cabo el trabajo de investigación.

En septiembre y diciembre del 2011 visité nuevamente la ciudad y desde el verano del 2012 vivo de forma estable en el enclave. Siempre desde mi diario de campo, presento algunas de las sensaciones y descripciones que anoté durante la estancia:

"Melilla es una ciudad de tránsito y espera. Paseando con mi bici por la Carretera Farhana a primera hora de la mañana suelo encontrar a ciudadanos marroquíes, tanto hombres como mujeres, que cruzando la frontera, entran en la ciudad para ir al trabajo. Igualmente suelo cruzarme con los migrantes del CETI que van a lavar coches en su "turno" de mañana. Llego al Campo sobre las nueve de la mañana para recoger a mis estudiantes. Del CETI hasta Melilla Acoge se tarda casi una hora: es el camino que hago con los que participan en mis talleres. Pasamos por un camino de tierra y polvo (...) que va paralelo al pequeño aeropuerto ciudadano. Un día, Louis, uno de los chicos que iba con nosotros, al ver despegar un avión, simuló lanzar una cuerda intentando alcanzar el avión para subirse a su cola. En los días de lluvia el camino se llenaba de charcos y fango dificultándonos el camino. Vemos el Monte Gurugú delante de nuestros ojos todo el tiempo, alguien me dijo que desde allí se ve la ciudad de Melilla y se sueña con alcanzar la meta. Algunos desconocen la lejanía de Melilla de la Península, así que la ilusión es mayor y aún más el posterior desconcierto. Suelen hablar entre ellos de sus aventuras, de las historias que han escuchado o vivido a lo largo del viaje (...) Apunto en la mente cada momento e información que puede ser útil para reconstruir esta cotidianidad. Mis talleres son parte de esta cotidianidad e, incluso, el 


\section{perifèria}

Número 17, diciembre 2012

\section{revistes.uab.cat/periferia}

camino que hacemos juntos lo es" (Marzo 2011).

Uno de los participantes, durante una entrevista, me comentó que, cuando esperaba en el Monte Gurugú su turno para pasar a Europa, veía su meta al alcance y que, una vez en la ciudad después de un primer momento de felicidad, la realidad le devolvió la incertidumbre. Dijo Michael durante la entrevista:

Michael: The time I came I wait on top of the Gurugu, so they showed us, to all the people that were there "that is Spain". So I was thinking that, when I will enter here, I thought it's Spain, it's finish; I didn't know that when I will enter here is another problem, because I have never been here before.

Francesco: What was your first impression of Melilla when you arrived?

M: When I arrived here I was very happy, you know, I find myself in Europe, so I was very happy, even if I had no money to call my people, I had to wait for some time, about one or two month to call to say that I am now in Europe, I said I am in Europe, I am in Spain (...) it's not the same here than in Morocco, I was eating, I was happy, the food was free of charge, they give us clothes free of charge, but I am staying here for too long (...)

F: So at the beginning it looks ok but...

M: Yes, but after a long time it's very difficult.

La sensación de la llegada a Europa se desvanece con el tiempo de estancia en la ciudad. Dependiendo del momento en el que se encontraba la persona entrevistada, era posible captar su estado de ánimo: si llevaba poco tiempo en el enclave, posiblemente tenía la confianza de salir pronto, percibía la estancia como un descanso en el caso en que su viaje hubiera sido largo y tortuoso; en el caso de que el entrevistado llevaba mucho tiempo en Melilla (ha habido personas que se han quedado cinco años) sus respuestas hacían hincapié en la falta de respuestas por parte del Gobierno, en la imposibilidad de saber cuándo dejarían la ciudad y el miedo a ser repatriado, el miedo constante a que llegara su cónsul por la mañana o la policía de madrugada. Un chico de origen asiático, que llevaba casi cinco años en Melilla me confesó durante una entrevista: "he perdido 7 años de mi vida, 5 años aquí y 2 de viaje. Yo estaba en mi país que tenía 22 años y ahora tengo 29, ¿qué he ganado?". El sentimiento de culpabilidad estaba constantemente presente en sus 


\section{perifèria}

Número 17, diciembre 2012

\section{revistes.uab.cat/periferia}

respuestas, se sentía culpable por no haber salido todavía. Me preguntaba "¿por qué este castigo?" y "¿cuál es nuestra culpa?".

Pude entrevistar a personas de los diferentes colectivos que estaban en el Campo: principalmente subsaharianos, argelinos y asiáticos. Entrevisté, en su mayoría, a hombres de entre veinte y treinta años. Pude entrevistar también algunas de las mujeres que se encontraban en el CETI en el momento de la investigación. El trabajo de investigación se dividió en las siguientes partes: una, dedicada a las entrevistas en profundidad; otra, a la observación; y finalmente una parte, tal vez la más importante para poder llevar a cabo las primeras dos, fue la realización de talleres artísticos con los migrantes y de la cual hablaré más adelante en el texto.

\section{Sobre mi rol como investigador y profesor.}

A propósito del acceso al trabajo de campo, es importante subrayar que me presenté, tanto a los migrantes como a los profesionales entrevistados, como un estudiante de doctorado. En el caso de los migrantes, mi primera presentación (generalmente en la primera clase de cualquier curso impartido) explicaba que estábamos haciendo talleres con el fin de mejorar su calidad de vida, en contra de la marginación que vivían, y que el proyecto se realizaba con vistas a mejorar su estancia. Igualmente especificaba que venía de la Universidad, que no era un trabajador ni del CETI, ni tampoco de las ONGs, sino que el proyecto estaba vinculado a la Universidad de Granada. De igual modo, contaba mi trayectoria profesional y la voluntad de realizar muchas actividades en la ciudad. En ningún caso intenté ocultar mi rol de investigador, profesor de fotografía y mi pertenencia a la Universidad.

El trabajo de campo ha significado una larga reflexión, no sólo sobre la situación de los migrantes del CETI, sino también de forma introspectiva sobre la mía. Haciendo referencia a las auto-etnografías mencionadas en el texto de Khosravi (2007) Illegal traveller entre otros, he sentido la necesidad de reflexionar en más de una ocasión sobre la figura de investigador que he ido negociando, no sólo con los informantes - intentando cambiar mis códigos y ampliando mi percepción de la realidad, acercándome a ellos "using the terms and understanding of the members 


\section{perifèria}

Número 17, diciembre 2012

\section{revistes.uab.cat/periferia}

of this group" (Bravo-Moreno, 2003:626)-, sino también negociando conmigo mismo, en un esfuerzo continuo por equilibrar mi rol, teniendo siempre en mente la expresión de Velasco y Díaz de Rada (1997:5) "el investigador nunca trabaja solo como investigador, trabaja también como vecino, como amigo, como desconocido, como hombre y mujer (...) y con otros papeles que él se haya forjado o que le haya conferido el grupo que analiza y con el que convive".

\section{Sobre el proyecto de acción social "Reconstruir la vida en la frontera"}

Las relaciones sociales desarrolladas a lo largo del trabajo de campo, las dinámicas que se han llevado a cabo, han sido cruciales para la realización del mismo. De igual importancia ha sido mi rol en continua negociación entre investigador y profesor. La participación en los talleres por parte de los migrantes ha puesto en primer plano la posibilidad de hacer etnografía, partiendo de herramientas que tratasen de superar la barrera de poder que se puede establecer entre entrevistado y entrevistador. Negociando mi rol, sin mentir, he conseguido la entrada en espacios que, de otro modo, probablemente no podría haber conseguido. Probablemente mi rol de profesor de los cursos me proporcionó algún tipo de ventaja, por ejemplo, poder entrar en espacios reservados a los migrantes.

El hecho que me reconocieran como su profesor de fotografía fue una manera para ganar algún tipo de confianza. Los conocía por sus nombres y nacionalidades, y del mismo modo ellos sabían que era italiano, que estaba con un proyecto de la Universidad de Granada y que no trabajaba en el Campo, sino que los recogía para salir de allí y conocer la ciudad. La elección de realizar los talleres se debe, entre otras, a la consideración de que los medios artísticos son un vehículo de expresión que puede superar las limitaciones lingüísticas y ofrecer, en cambio, nuevos temas de análisis y nuevos enfoques. Por ejemplo, durante un curso de vídeo un grupo de subsaharianos que participaba puso en escena la última parte de su viaje migratorio; y la forma en que representaron este viaje fue el punto de partida de una de las entrevistas que realicé. En el vídeo, uno de los autores me explica porqué habían elegido esta temática:

"In this film we are showing, to you, an example of what happens to us in the trip, because when we are up in the mountain (Gurugu) nobody can see us, 


\section{perifèria}

Número 17, diciembre 2012

\section{revistes.uab.cat/periferia}

and if someone find us they can take us to prison. That's why when we enter (in Melilla) we have to show you an example of the reality (of our experience) we live".

Los trabajos realizados durante los talleres podían así ser un reflejo de lo que sentían y una manera de explicarnos, en forma de vídeo, lo que les sucedía. En otros casos, los talleres $\mathrm{y}$, sobre todo las imágenes que representaron los migrantes, ofrecieron puntos de reflexión orientados a cancelar estereotipos, brindándonos una visión distinta de su manera de vivir la estancia en el CETI. En algunos autorretratos, los hombres resaltaban su valor a través de una pose seria 0 enseñando su cuerpo.

Por otro lado, es necesario reflexionar también sobre el hecho que los migrantes (los que participaron en los talleres al menos) veían en mí una figura constantemente presente en la ciudad; era el que ofrecía diferentes cursos a lo largo del año, siendo de este modo, no una persona de paso o alguien que quería sacar información para luego marcharse, sino alguien que estaba allí para ofrecer algo (una formación) y que estaba interesado en ellos. En más de una ocasión los participantes me dieron las gracias por brindarles la posibilidad de una formación, por darles la oportunidad de aprender algo que no sabían o, sencillamente, por darles una excusa para salir del Campo.

Ganar la confianza de las personas migrantes fue un reto importante en el trabajo; ellos viven bajo una presión que hace que desconfíen de cualquier persona, tienen miedo a que cualquier cosa que digan pueda volverse en su contra.

El proyecto de acción social que realicé con la financiación del CICODE (Centro de Iniciativas de Cooperación al Desarrollo) de la Universidad de Granada, en colaboración con la ONG Melilla Acoge, se llevó a cabo en el periodo de mi estancia y se plasmó en torno a una serie de cursos/talleres con los migrantes, relacionados con el arte (pintura, teatro) y los medios de comunicación (fotografía, vídeo, radio). Todas las acciones compartían un enfoque participativo. Igualmente, a raíz del proyecto surgió la posibilidad de realizar jornadas y una exposición con el material del proyecto.

La participación activa de los migrantes en los talleres constituyó uno de los ejes 


\section{perifèria}

Número 17, diciembre 2012

\section{revistes.uab.cat/periferia}

fundamentales del trabajo. Las metodologías participativas tienen el objetivo de llevar a cabo cambios para y con los participantes en el estudio (Pain, Francis, 2003:46); están orientadas a crear un espacio donde poder escuchar las voces de los marginados, con la obligación de dar acceso a estas voces y creando lugares donde pueden ser escuchadas, con el fin de remarcar los problemas y buscar soluciones que lleven a un cambio y a una transformación (Mand 2012:151). En este contexto, las técnicas audiovisuales suscitan la creatividad y la innovación de los participantes (De Lange 2008:111).

La acción que se tituló "Reconstruir la vida en la Frontera", y que se debe incluir en la investigación, escogió algo de las técnicas participativas como: Participatory Action Research (PAR), Participatory Video (PV), Participatory Art (PA), photovoice etc., adaptándolas y transformándolas en la propia acción.

A lo largo del proyecto y en distintos talleres, se utilizaron los medios audiovisuales con los migrantes que participaron. En el mismo vídeo que he citado anteriormente, los migrantes describieron a través de la lente de la cámara su llegada a la ciudad a través del mar. Explicaron en una entrevista posterior a la grabación, que hablan de este viaje porque quieren narrar, de forma autobiográfica, lo que están dispuestos a sufrir para llegar a Europa. Cuentan a través de las imágenes de la breve película cómo en la ciudad compran la zodiac, con la que cruzan los kilómetros que los separan de Melilla. En la representación, regatean con el vendedor el precio del barco y luego, una vez comprada la embarcación, se dirigen a la playa donde los policías controlan que nadie pase. A escondidas se acercan a la playa, inflan la zodiac y se meten en el mar. Europa está más cerca. El viaje, la aventura, como les gusta llamarla, es contada con heroicidad y exaltación, y también a través del sufrimiento que se vive en Marruecos, como en las otras etapas. Comentaba Chuck- $B$, un chico subsahariano de unos veinte años y uno de los autores del cortometraje, a propósito del video:

"We are doing this film because many African people are so tired. We pass through Morocco and the mountain called Gurugú, we suffer, is a very bad place; (to reach Europe) we buy a boat and try to put it in the water and cross; this is the reason of the film: to show to the Spanish people, to the 


\section{perifèria}

Número 17, diciembre 2012

\section{revistes.uab.cat/periferia}

European, and to the world, how the black people can spend their life to enter in Europe, because in our country we are suffering and that is why everybody here is trying to get in Spain and to get to Europe".

Chuck-B participó en un curso de fotografía y en otro de vídeo, y me pidió que lo escuchara cantar y le grabara algunos videos clips. Salió de Melilla antes de la navidad del 2010, después de unos pocos meses en la ciudad. Recuerdo hablar con él algunas semanas antes; estaba seguro de poder alcanzar la Península cuanto antes. En una de las entrevistas que grabamos junto a los vídeos clips, narró otra parte del viaje hasta Melilla:

I leave my country because of fighting, that's why I leave my country to try to go to Europe. I stay in Mali for one month, then I travel to Mauritania where I stay three months and then directly to Morocco. I stay six months there. I needed money to reach Europe (...) I had to get in a small boat with other ten people. I thought he was mad and that we could die. But I give myself to God and pray God and after more than one day we reach Melilla. The Guardia Civil caught us. In the police station they ask me what I wanted to do here and I said that in Africa we are poor and we always fight. Two days after I was in the CETI".

A veces los migrantes pueden ofrecerse 'voluntariamente' para ser expulsados a los CIE (Centro de Internamiento para Extranjeros) de la Península. Cada lunes, algunos migrantes lo intentan $y$, dependiendo de la procedencia y de los acuerdos que mantiene España con esos países ( $y$ de la suerte), consiguen salir hacia un Centro de Internamiento. Desde allí, después de sesenta días en este otro Campo, podrán ser devueltos a sus países o alcanzar la "libertad", y una orden para dejar el país que posiblemente no respetarán, empezando su estancia (irregular) en España. Así que Chuck-B intentó la suerte y se ofreció voluntario. Fue trasladado a la Península y después de su permanencia en un CIE, alcanzó la libertad, posiblemente en este momento estará trabajando $y$, con suerte, conseguirá regularizar su situación en algunos años. 


\section{perifèria}

Número 17, diciembre 2012

revistes.uab.cat/periferia

\section{Observación participante}

Utilizo las herramientas etnográficas para dar forma al trabajo; lo que resulta de este esfuerzo es un texto que nace de la voluntad de conocer y re-socializarme en este contexto. Es importante poner de manifiesto la importancia de la participación en la vida diaria de los sujetos estudiados, ya que como sostiene Guber (2011:55): "tal como un juego se aprende jugando, una cultura se aprende viviéndola. Por eso la participación es la condición sine qua non del conocimiento sociocultural". Fundamentalmente, reflexioné sobre algunos aspectos en concreto como: la condición de aislamiento; las relaciones entre/intra grupales; el control ejercitado; el sentimiento de pertenencia; y otros factores que son claves en la continua remodelación de la identidad, entendida en un complejo sistema de apropiación y creación individual de significados, teniendo en consideración "la intersección entre cultura, estructura social y biografía" (Bravo-Moreno 2002:3).

La recopilación de información fue posible gracias a mi inmersión en el contexto, principalmente, a través de: la entrada diaria en el Centro de Estancia Temporal y la conversación con los residentes; las visitas a las chabolas; la realización de cursos y talleres con las personas migrantes; jugar al fútbol con el equipo del CETI; participar los domingos en la misa con ellos y ellas; realizar entrevistas en profundidad con los informantes; grabar videos y canciones, y realizar distintas actividades en el espacio público; tomar cafés, acudir a las manifestaciones y a los eventos que implicaban a los colectivos migrantes; y por último, participar en la vida pública de la ciudad como un ciudadano más. La falta de sistematicidad del trabajo de campo etnográfico, como afirma Guber, garantiza su fiabilidad a través de la observación participante, que es continua e integrada en el contexto y que:

"consiste precisamente en la inespecificidad de las actividades que comprende: integrar un equipo de fútbol, residir con la población, tomar mate y conversar, hacer las compras, bailar, cocinar, ser objeto de burla, confidencia, declaraciones amorosas y agresiones, asistir a una clase en la 


\section{perifèria}

Número 17, diciembre 2012

\section{revistes.uab.cat/periferia}

escuela o a una reunión del partido político. En rigor, su ambigüedad es, más que un déficit, su cualidad distintiva" (Guber 2011:51).

La observación se llevó a cabo en diferentes espacios claves de la ciudad autónoma, tomando en consideración, tanto los espacios compartidos entre migrantes y ciudadanos (la iglesia, el campo de fútbol, y también las calles, las plazas), como los espacios reservados a los migrantes (el CETI y las Chabolas que surgen cerca del mismo).

Me acerqué a las Chabolas por primera vez un día de otoño del 2010, con tres chicos que participaban en un taller de vídeo participativo que les impartía. Uno de ellos quería mostrar parte del día a día de los migrantes a través de uno de los espacios claves, las Chabolas, que ellos mismos llamaban la "fábrica de los niños". Estos espacios surgían a pocos cientos de metros del Campo. A lo largo de mi estancia prendieron fuego algunas de las Chabolas y luego fueron demolidas. Constituían el lugar de ocio de los migrantes. De mi diario de campo anoto algunas de las emociones que sentí aquella primera vez allí:

"Acabo de volver de las chabolas. Hay basura acumulada en todos lados. Hay dos zonas divididas por la carretera, en un lado unas veinte chabolas construidas en una pequeña colina, sin ningún orden o sentido, al otro lado una fila de chabolas construidas de la misma forma (con plásticos y maderas). En el tiempo que hemos transcurrido allí hemos visitado algunas y hablado con algunos migrantes que estaban en aquel momento (...) He estado allí con algunos chicos del curso de audiovisual, que me explican algunas de las normas de este espacio y me cuentan que ellos no suelen ir (...). Sentado en un sofá bebiendo con algunos compañeros, un chico muy alto (que participa también en el mismo curso) me pide entrevistarle por la mañana ya que por la tarde no está en condiciones de hablar, me cuenta un poco de su familia, de su soledad (...). Las Chabolas no resultan ser un agradable lugar de encuentro, sino que una especie de gueto." (de mi diario de campo, noviembre 2010). 


\section{perifèria}

Número 17, diciembre 2012

\section{revistes.uab.cat/periferia}

Recuerdo que, en cambio, la primera vez que entré en un $\mathrm{CETI}^{5}$, fue todo tan rápido que casi no pude memorizar los colores de las paredes, ni distinguir las caras de los que entrevistaba. El aire cálido de verano y las descripciones del entorno que proporcionaba el director del Centro daban al espacio un aire de normalidad que, sólo en un segundo momento entendí que enmascaraban otras sensaciones (desesperación y clausura) que sentían muchos de los residentes.

Es cierto que los migrantes pueden salir durante el día del Campo, pero en la realidad muchos de ellos se limitan a estar en el Campo o en las cercanías. Algunos de los migrantes trabajan limpiando coches en las calles del centro ciudad. A pesar de eso, su presencia en el espacio público es prácticamente imperceptible. Uno de los entrevistados en Melilla, a propósito de su trabajo me decía:

"The only advantage that we have is that they allow us to come out and wash some cars, and that is what we are doing: wash cars, and we get something, and we can use it to call our families and then we can buy some dresses".

La estancia de los residentes debería ser breve, pero la mayoría de las personas entrevistadas llegaron a estar al menos dos años en el Campo antes de ser trasladados a la península. Es posible que los migrantes perciban, en un primer momento, su estancia como una etapa más de su trayecto migratorio (aunque al principio puedan creer haber alcanzado Europa, se dan cuenta que su vida aquí está lejos de lo que soñaban), pero más adelante resulta una existencia atrapada en una especie de limbo. El mismo informante me dijo "you cannot go in front when you wish and not go behind, that is what we are talking about, we are just living in a hole, that you cannot go behind or in front". La sensación es la de estar "en medio", de no haber llegado al destino, de tenerlo cerca, pero al mismo tiempo de estar con la tensión y el miedo de que te deporten a tu país de un momento a otro.

\footnotetext{
${ }^{5}$ En mayo del 2005 pude visitar y grabar algunas imágenes del CETI de Ceuta mientras realizaba mi trabajo final de carrera.
} 


\section{perifèria}

Número 17, diciembre 2012

\section{revistes.uab.cat/periferia}

En un continuo proceso de intentos y acercamientos fui entrando en su mundo, conociendo estas sensaciones descritas y también sus horarios y los lugares que frecuentaban. De este modo, la observación participante se ha plasmado en torno a una constante participación en las vidas de los migrantes, en la búsqueda de su visión de su mundo. Observando la cotidianidad, caracterizada por la soledad y la rutina, "utilizando metodologías etnográfico-cualitativas con el fin de reconstruir el día a día en un grupo específico de inmigrantes" (Bravo-Moreno 2003:626); profundizando en la observación de algunos momentos claves, en los espacios públicos. Y, finalmente, interpretando los acontecimientos a los que he asistido: desde la formación teatral de un grupo de migrantes y la sucesiva puesta en escena de una obra, a la trágica muerte de tres chicos subsaharianos en una chabola situada a cientos de metros del Campo y las consiguientes consecuencias en la ya tensa situación en el Campo; desde las manifestaciones de los grupos de asiáticos y de los subsaharianos, hasta los entrenamientos de fútbol con el equipo del CETI, donde acudí durante el otoño-invierno 2010-2011.

Como subrayan Velasco y Díaz de Rada (1997:2) la observación participante "no subsume al trabajo de campo, pero no sería posible fuera de él", tanto que los dos están estrictamente relacionados, siendo el trabajo de campo el único medio para la observación participante. Hammersley e Atkinson $(1983,1994)$ argumentan que toda investigación social es una forma de observación participante, ya que no es posible estudiar el mundo social sin formar parte de éste; en la misma línea, la observación participante es descrita por los autores como un modo de estar en el mundo característico de los investigadores.

En diferentes ocasiones, me vi en la tesitura de tener que enfrentarme a la decisión de posicionarme del lado de los migrantes cuando reclamaban algo justo, o por otro lado, a condenar estas acciones cuando así lo creía correcto; esto siempre desde un punto de vista personal frente a la situación.

La observación de la realidad se ha presentado como un puzzle complejo, compuesto de piezas escondidas y que, sólo con una mirada más profunda, he sabido colocar. Es decir, la realidad observada, la ciudad de Melilla en sus múltiples dimensiones, así como el Campo, son espacios de una complejidad elevada. Mi involucración en la escena social ha sido inevitable; por más que haya intentado 


\section{perifèria}

Número 17, diciembre 2012

\section{revistes.uab.cat/periferia}

quedar al margen, sólo como un observador curioso, he terminado siendo parte de la acción.

Al final de mi estancia he participado en distintas entrevistas en los medios de información de la ciudad interesados en el trabajo. A pesar de mi personal reticencia a hablar, he formado parte de la acción, impulsado por el mismo ideal de cambio a raíz del trabajo, y por la misma curiosidad que me llevaba a observar y entrar en los espacios de una ciudad extraña para mí.

Al mismo tiempo, dentro del CETI, aunque sólo fuera de oídas, tanto los residentes ${ }^{6}$ como el personal del centro, conocían lo que estaba haciendo $y$, a menudo, me paraban por la calle personas interesadas en participar en los talleres. En esta línea, como sostiene Cerri (2010:5):

"el antropólogo se encuentra así obligado, durante el trabajo de campo, a estar entre dos mundos, el suyo y el de los otros, y a adoptar un rol para el mejor desarrollo de la investigación y para el mejor desarrollo de su vida privada durante el trabajo."

La larga estancia me permitió alcanzar, probablemente, un cierto grado de rapport, como lo define Malinowski (1961), es decir, una cierta empatía entre el investigador y los informantes debido a la larga y continuada estancia. El rapport es importante en la observación, ya que puede permitir acceder a información que permanecería oculta al observador o entrevistador casual (Carozzi 1996:43). Paradójicamente, por otro lado, en algunas situaciones pasé de ser observador a ser observado.

En distintas ocasiones fui parado por la policía en la calle cuando estaba con los participantes en los cursos, e igualmente, por otro lado, controlado por los migrantes, que en algunas ocasiones veían mi trabajo como una amenaza. A menudo en el Campo, si hablaba con una persona se me acercaba otra que, de forma disimulada, se ponía a escuchar nuestra conversación. En consecuencia, debido al control, se generaba cierta desconfianza general entre compañeros

\footnotetext{
${ }^{6}$ Tanto la institución como los medios de comunicación denominan a los migrantes que viven en el CETI, "residentes". Utilizo esta expresión, a pesar del hecho que los migrantes no quieren residir en el Centro, como herramienta lingüística para no repetir de forma asidua la palabra migrante.
} 


\section{perifèria}

Número 17, diciembre 2012

\section{revistes.uab.cat/periferia}

(continuamente en las conversaciones hablaban de los "chivatos") y con las personas que no eran migrantes.

\section{Tipología de entrevistas}

Realicé entrevistas a los migrantes, al personal que trabaja en el Centro de Estancia de Inmigrantes y a exponentes de las ONGs locales que se ocupan de inmigración. Sobre las entrevistas realizadas, señalar en primer lugar que han sido una herramienta útil, sobre todo cuando éstas prescindían del ámbito formal. En este sentido, todas las entrevistas con las personas migrantes las he llevado a cabo fuera de los espacios institucionales, como pueden ser el CETI o las ONGs; sí he preferido encontrar, en espacios neutrales y públicos, el lugar más adecuado para realizarlas. Este aspecto lo he considerado con el fin de establecer un equilibrio entre entrevistado y entrevistador, escapando de aquellas dinámicas que podrían desequilibrar la entrevista. Así que en buena parte, las entrevistas se han llevado a cabo en el bar del Campus de la Universidad de Granada (UGR) en Melilla o en otros lugares, como jardines u otras zonas públicas de la ciudad.

Por el contrario, las entrevistas al personal del CETI y a los exponentes de las ONGs se han llevado a cabo en sus lugares de trabajo. La importancia de las entrevistas (sobre todo las entrevistas a los migrantes) me ha permitido "establecer un contacto personal con los sujetos estudiados en situaciones relativamente controladas y obtener una amplia y rica producción de discurso", recuperando la cita de la narración de Márquez-Lepe (2006:174) a propósito de su trabajo de campo. Pero al mismo tiempo, no han sido sólo las entrevistas las que han producido "discurso", sino el contexto, el momento y el entorno de las entrevistas, el antes y el después. Es por ello que ha sido de gran ayuda el hecho que, en la casi totalidad de los casos, conocía a las personas entrevistadas porque participaban en las actividades (tanto talleres de vídeo, foto, pintura etc.) pudiendo hablar con ellas en distintos momentos. La información, de este modo, no se limitaba a la de la entrevista. El hecho de conocer a la persona, por ejemplo, podía ser de ayuda para el desarrollo de la misma, así como para la misma elección del candidato.

En referencia a las entrevistas a los miembros de ONGs y al personal del CETI, 


\section{perifèria}

Número 17, diciembre 2012

\section{revistes.uab.cat/periferia}

pude realizar prácticamente todas las entrevistas prefijadas. En el caso de los trabajadores del CETI, las entrevistas no se grabaron. Como ocurrió en el caso de los migrantes, el acceso al personal de estas instituciones, se debió al conocimiento personal a lo largo del trabajo de campo. En el caso de los trabajadores de las ONGs, a veces teníamos amistades en común y nos encontrábamos en las manifestaciones o reuniones varias, y eso facilitó el contacto.

Recuerdo que las primeras entrevistas con los migrantes, sobre todo en el primer acercamiento al campo, anteriores a mi traslado a la ciudad, fueron poco interesantes debido a la falta de confianza con los entrevistados; conocer (y ser reconocido) fue una vía de acceso importante a los informantes, y eso fue posible gracias a la acción social y al enfoque que elegí. Con el tiempo mi grado de integración alcanzó un mejor nivel, generando confianza en los entrevistados, gracias también a la labor de algunos de los informantes que, confiando en mí, garantizaban delante de los demás mi posición. La relación que establecí con los informantes, tanto en las entrevistas como en los cursos, pretendía mantener un equilibrio que me permitiese tener la confianza del colectivo. Por otra parte, fue difícil no tomar partido en las situaciones que se presentaban. Como sostiene Ana Bravo-Moreno, la importancia del equilibrio en las relaciones de poder entre entrevistado y entrevistador se basa en distintos puntos. La autora afirma:

"I think it is important to establish as much as possible an equal relationship with the interviewee. Part of that equality is to listen, to make one accessible and approachable. This is particularly the case when dealing with life stories. When the participant agrees to tell her story, she agrees to expose herself to a stranger, the researcher. My response could not be detached but receptive, flexible, appreciative and responsive when the interviewee found it necessary to ask personal questions. Both parties relied on respect of the other. Vulnerability played an important role in the interview. I think the participant must feel that the researcher is willing, if the case arises, to give some information about her as part of equalising the power in the relationship" (Bravo-Moreno 2003:635).

En las entrevistas he preguntado a menudo sobre su vida en el CETI y si creen que 


\section{perifèria}

Número 17, diciembre 2012

\section{revistes.uab.cat/periferia}

saldrán pronto, o si saben cómo funciona el mecanismo de las expulsiones. Con frecuencia también han sido ellos quienes me han preguntado a mi cuándo saldrán de Melilla. En ningún caso pude mentir, de hecho no sabía cuando iban a salir. Ben, otra de las personas migrantes con las que pude hablar a lo largo de toda mi estancia, me confesó que intentaba sobrellevar la situación y que a veces no sabía cómo hacerlo. En este intercambio de frases que reproduzco abajo, Ben reflexiona sobre el año que ha transcurrido a la espera de su salida:

Francesco: Desde hace un año que estás aquí, ¿cómo te va la vida?

Ben: He encontrado bastante amigos desde que he llegado aquí, simpatizo con muchas personas de muchas nacionalidades y en el CETI tengo a muchos amigos. Intento llevarme bien con muchas personas porque entiendo que es aquí que estoy, lo mejor es estar bien con quien sea para vivir y no comerse la cabeza. Pero para mí de vez en cuando se hace difícil, sí, se hace un poco difícil para mí. Bueno, durante el primer año he hecho lo que pude. En un año ¿qué hice? Hice cursos de lengua española, sí, he asistido también a las fiestas de inmigrantes, (...) a la Semana Santa, he aprendido a bailar sevillanas (...) también hice los cursos de pintura y he hecho la formación en la granja escuela. Bueno en la mente, yo pensaba que después de todo eso, podría irme fácilmente pero veo que nada cambia, es la misma situación. Y va como a bajar, intenta afectarme (esta situación), pienso que es eso, prueba a afectarme pero intento ser fuerte. Me ves muchas veces, "haz deporte, haz esto y el otro", es para no pensar demasiado, y hago otra cosa. Es un poco mi vida en Melilla. $Y$ el problema es que estás en un sitio, no puedes ir adelante, no puedes volver, no sabes dónde está tu vida. Eso pesa.

F: Sí.

B: Sí, duele.

F: ¿Piensas que vas a estar mucho más tiempo parado aquí?

B: ¿Me preguntas si voy a pasar aquí mucho más tiempo? Yo no lo sé eso.

La situación de Ben, como la de muchos otros, en este sentido se caracteriza por la precariedad y la falta de información sobre su destino. No saben cuándo saldrán y 


\section{perifèria}

Número 17, diciembre 2012

revistes.uab.cat/periferia

tampoco saben qué hacer mientras. $Y$ eso parece indicar que su condición irregular no le da el derecho a saber cuándo saldrán de aquí. Otro de los entrevistados, éste de origen asiático, me preguntó directamente a mí por qué ellos no salen de Melilla.

F: (...) Ilegará el momento que desde Madrid dirán "te has ganado la península" y tú habrás estado tanto tiempo preguntándolo porque tú no, y ellos un día, sin razón, aparente te dejaran entrar.

S: por eso yo todavía vivo, un día me podrán llamar, pero hasta cuándo ¿cuándo va a llegar este día? Esta es mi pregunta. Una persona en 3 ó 6 meses puede ganarse la libertad, una persona en 7 días ha conseguido la residencia y nosotros en 5 años no hemos conseguido nada.

F: no hay culpas

S: ¿por qué nosotros seguimos aquí?

Un último factor interesante ha sido la elección del idioma de las entrevistas. A pesar de que algunos de los entrevistados permanecían en Melilla desde hacía años, su nivel de castellano era bajo. Debido a esto, las entrevistas se realizaron en el idioma que permitiese al entrevistado expresarse de forma más detallada, así que las entrevistas se llevaron a cabo tanto en castellano, en algunos casos, como en inglés y francés.

Finalmente, decir que la investigación que he llevado a cabo ha tomado en consideración un colectivo muy vulnerable y por esta razón, desde el principio, intenté establecer reglas y éticas de comportamientos para no vulnerar la privacidad de los informantes. Ha sido complejo trabajar durante un tiempo prolongado en un ambiente como el que he hallado en Melilla. Partiendo de una firme consideración por lo que estaba haciendo, tutelando los intereses de todos los agentes involucrados, tanto de los migrantes como de los informantes no-migrantes (trabajadores de las ONGs), ha prevalecido siempre el respeto por la privacidad de un colectivo vulnerable, antes de cualquier voluntad de narrar e indagar en los acontecimientos. 


\section{perifèria}

Número 17, diciembre 2012

revistes.uab.cat/periferia

\section{Conclusión}

La metodología del trabajo ha querido remarcar la importancia de la participación en la observación. De esta forma, desde el punto de vista metodológico, se utilizan las herramientas etnográficas en un trabajo cualitativo que se sirve de la observación participante y de las entrevistas en profundidad. En la observación se ha intentado excavar en el conocimiento de la cotidianidad del contexto, a través de la participación en la vida en el margen, por ejemplo: frecuentando de forma continuada el CETI; presenciando las manifestaciones; acudiendo a los lugares de rezo; así como visitando las chabolas. Lugares, todos ellos, frecuentados por el sujeto estudiado. De algún modo he intentado conciliar mi estancia con las acciones cotidianas de los migrantes, en un intento de impregnarme de ellas.

Al mismo tiempo, mi presencia constante, a través de la realización de numerosas actividades relacionadas con el arte y los medios audiovisuales, me han permitido conocer de primera mano a las personas entrevistadas antes de realizar las entrevistas. En cierto modo, las actividades han sido un filtro hacia las entrevistas. Mi rol, entre investigador y profesor, continuamente negociado, me ha permitido: por un lado, el distanciamiento de algunos roles percibidos de modo sospechoso por los migrantes; y por el otro, mi presencia constante y prolongada en la escena, que me ha permitido tener acceso a numerosas informaciones y hechos fundamentales para llevar a cabo el trabajo de campo.

Por otra parte, desde el punto de vista metodológico, un hallazgo importante ha sido la participación de los migrantes en el análisis y en la recopilación de la información. A través de una serie de acciones (principalmente cursos y talleres) se ha recopilado una serie de narraciones y relatos que los migrantes han hecho, en forma de autobiografías o de imágenes donde se describían diferentes momentos de la estancia en la ciudad, así como reconstrucciones del pasado o de expectativas de futuro. Este material, por ejemplo, me ha permitido reflexionar sobre aspectos de la construcción identitaria, analizando otros importantes como: el sentimiento de pertenencia y la reconstrucción del pasado; el viaje migratorio y, en general, otros acontecimientos que los migrantes que participaban en las actividades 


\section{perifèria}

Número 17, diciembre 2012

revistes.uab.cat/periferia

protagonizaban, en muchos casos, de forma espontánea, utilizando otras veces elementos de ficción.

Finalmente decir que, los relatos en primera persona de las personas migrantes y mi papel en la investigación, han intentado traspasar las barreras que pueden surgir entre el entrevistador y el entrevistado. El análisis de estas narraciones en primera persona, ha intentado extraer las informaciones más importantes, buscando en ellas las respuestas a los objetivos establecidos, es decir, la investigación de la construcción identitaria de personas que viven en esta situación de limbo (o liminal) caracterizada por el control, la incertidumbre y el intento de despersonalización, puesto en marcha por la institución a través de su irregularización.

\section{Bibliografía}

Atkinson, P., Hammersley, M (1994). Etnografía. Métodos de investigación. Barcelona: Paidós Básica.

Bondanini, F. B. (2011). Migración de tránsito y pasaje a Europa. El caso de Melilla. I Congreso Internacional sobre Migraciones en Andalucía, Granada, pp.613-621

Bravo-Moreno, A. (2002). Approaches to International Migration. Immigrant Women, and Identity. Migraciones Internacionales, 1(2), 62-91.

Bravo-Moreno, A. (2003 ). Power Games between the Researcher and the Participant in the Social Inquiry. The Qualitative Report, 8(4), 624-639.

Cerri, C. (2010). La importancia de la metodología etnográfica para la investigación antropológica. El caso de las relaciones de valores en un espacio asociativo juvenil. Perifèria, 13, 1-32.

Guber, R. (2011). La etnografía. Método, campo y reflexividad. Bogotá: Grupo Editorial Norma.

Khosravi, S. 2007. 'The "Illegal" Traveller: An Auto-Ethnography of Borders', Social Anthropology 15(3): 321-34

Malinowski, B. (1995). Los Argonautas del Pacífico Occidental: un estudio sobre comercio y aventura entre los indígenas de los archipiélagos de la Nueva Guinea 


\section{perifèria}

Número 17, diciembre 2012

revistes.uab.cat/periferia

melanésica: Península.

Marcus, G. E. (2001). Etnografía en/del sistema mundo. El surgimiento de la etnografía multilocal. Alteridades, 11(22), 111-127.

Márquez Lepe, E. (2006). La gestión política de la diversidad cultural en España: análisis de los discursos parlamentarios sobre inmigración. Universidad de Granada, Granada.

Rahola, F. (2003). Zone definitivamente temporanee. Verona: Ombre corte.

Turner, V. W. (1988). El proceso ritual. Madrid: Taurus Alfaguara.

Velasco, H., Díaz deRada A. (1997). La lógica de la investigación etnográfica: un modelo de trabajo para etnógrafos de la escuela. Valladolid: Trotta. 